\title{
Foraging distribution of a tropical seabird supports Ashmole's hypothesis of population regulation
}

\author{
Steffen Oppel ${ }^{1} \cdot$ Annalea Beard $^{2} \cdot$ Derren Fox $^{3} \cdot$ Elizabeth Mackley $^{1} \cdot$ Eliza Leat $^{3}$. \\ Leeann Henry ${ }^{2} \cdot$ Elizabeth Clingham ${ }^{2}$ - Nathan Fowler ${ }^{3}$ • Jolene Sim $^{3}$. \\ Julia Sommerfeld $^{4} \cdot$ Nicola Weber $^{3} \cdot$ Sam Weber $^{3} \cdot$ Mark Bolton $^{1}$
}

Received: 20 November 2014 /Revised: 10 March 2015 / Accepted: 11 March 2015 /Published online: 2 April 2015

(C) (C) Crown Copyright 2015

\begin{abstract}
Many animals reproduce in large aggregations, which can vary in size from dozens to millions of individuals across species, time and space. The size of breeding colonies is a complex trade-off between multiple costs and benefits to an individual's fitness, but the mechanisms by which colony size affects fitness are still poorly understood. One important cost of breeding in a large colony is the spatial constraint in resource use due to the need to regularly return to a central location. Large aggregations, like seabird breeding colonies, may therefore deplete food resources near the colony, forcing individuals to travel farther to find food, which may ultimately limit their reproductive output and population size. This hypothesis, proposed in 1963 by Ashmole for tropical oceanic islands, has so far not been tested at tropical seabird colonies, where food availability is less predictable than in colder waters. We compare the foraging distribution of a common tropical seabird, the masked booby Sula dactylatra, breeding on two islands in the South Atlantic that differ in the size of the
\end{abstract}

Communicated by C. R. Brown

Electronic supplementary material The online version of this article (doi:10.1007/s00265-015-1903-3) contains supplementary material, which is available to authorized users.

Steffen Oppel

steffen.oppel@rspb.org.uk

1 RSPB Centre for Conservation Science, Royal Society for the Protection of Birds, The Lodge, Sandy, Bedfordshire SG19 2DL, UK

2 Environmental Management Division - Marine Section, St. Helena Government, Jamestown STHL 1ZZ, Saint Helena

3 Ascension Island Government Conservation Department, Georgetown ASCN 1ZZ, Ascension

4 Research and Technology Centre, University of Kiel, Büsum, Germany breeding seabird community by 2 orders of magnitude, but are surrounded by similar oligotrophic waters. Foraging trips from the island with the smaller colony were on average $221 \mathrm{~km}(61 \%)$ and $18.0 \mathrm{~h}$ (75\%) shorter because birds from the smaller colony rarely spent the night at sea and foraged on average $64 \mathrm{~km}$ ( $46 \%$ ) closer to the colony. Energy expenditure was significantly lower, and nest survival higher (47 vs. $37 \%$, $n=371$ ) on the island with the smaller colony. These results are fully consistent with the predictions from Ashmole's hypothesis and indicate that competition for food around tropical oceanic seabird colonies may indeed be a limiting factor for populations. Identifying important feeding areas for seabirds based on their foraging range may need to account for colony size of both the target and potential competitor species.

Keywords Ashmole's halo - Central-place forager . Coloniality $\cdot$ Interference competition $\cdot$ Hidden Markov model $\cdot$ Marine protected area $\cdot$ Top predator

\section{Introduction}

The evolution of aggregated breeding systems, generally referred to as colonies, is believed to have benefited from information exchange, cooperation, efficient defence against predators and several other benefits (Wittenberger and Hunt 1985; Danchin and Wagner 1997; Brown and Brown 2001). Despite advantages to breeding in large aggregations, there are distinct costs such as competition for resources or disease transmission, and the complex trade-off between costs and benefits leads to large variation in colony size across species, space and time (Wittenberger and Hunt 1985; Brown and Brown 2001). However, the mechanisms that determine the size of colonies are generally poorly understood (Brown and Brown 1996; Brown et al. 2013). 
To better understand why colonies vary in size, it is important to study how colony size affects the fitness of individuals. Reproductive output is a useful measure of fitness that can synthesise the various costs and benefits of colony size (Danchin and Wagner 1997), and one direct mechanism linking reproductive output to colony size is increased competition for food. Ashmole (1963b) hypothesized that as a consequence of individuals in a colony exploiting the surrounding resources, as colonies grow, food can potentially become locally depleted, which would lead to lower reproductive output and therefore regulate population size. However, due to logistical difficulties in quantifying the amount of available resources, there have been few conclusive studies demonstrating that food is actually depleted by the individuals in a colony (Birt et al. 1987; Brown and Brown 1996; Ainley et al. 2003). Prey depletion may require individuals nesting in large colonies to travel farther to find un-depleted patches where they can obtain food at a sufficiently fast rate to provision their chicks (Lewis et al. 2001; Ainley et al. 2003, 2006), and travel distance can serve as useful correlative evidence for the existence of food depletion effects. However, there is still relatively little evidence from birds to show that foraging trip length increases with colony size (Brown and Brown 1996, 2001; Wakefield et al. 2013). Recent advances in tracking technology have opened opportunities to record foraging trips in great detail and therefore explore the mechanisms and fitness consequences of colony size (Burger and Shaffer 2008; Hebblewhite and Haydon 2010).

Ashmole (1963b) hypothesized that one group of colonially nesting birds that may suffer from food depletion is seabirds, which nest on land but obtain most of their food from the surrounding sea. During the breeding season, seabirds require access to sufficient food to ensure growth and survival of offspring, and these food resources must be accessible from the centrally placed colony location. Although Ashmole's hypothesis specifically referred to seabird populations on tropical oceanic islands, tests of this hypothesis have so far focussed on species breeding at high latitudes (Birt et al. 1987; Lewis et al. 2001; Ainley et al. 2003, 2006; Ballance et al. 2009; Elliott et al. 2009; Szostek et al. 2013), or on theoretical models (Gaston et al. 2007). However, seabird competition for food in tropical waters may differ from higher latitudes for three important reasons: first, compared with colder waters, tropical seas have generally low phytoplankton densities without pronounced seasonal pulses in food availability for higherlevel consumers, and prey availability for seabirds is spatially less predictable than in temperate or polar waters (Ainley and Boekelheide 1983; Weimerskirch 2007). Second, competition for food will be most pronounced during the chick-rearing period when food requirements are highest, but many tropical seabirds can nest year-round, and the temporal dilution of the nesting period may reduce competition. Finally, most tropical seabirds acquire their prey near the surface and rely on subsurface predatory fish or mammals to drive smaller prey organisms to the surface (Ashmole 1971; Diamond 1978; Au and Pitman 1986). Because these feeding associations occur only temporarily, interference competition at ephemeral food sources is more likely than exploitative competition leading to an actual depletion of the prey base (Diamond 1978). However, the foraging ranges and spatial distribution of tropical seabirds are still comparatively poorly known (Weimerskirch 2007), and existing studies either focussed on single islands or were unable to resolve whether differences between islands were due to colony size or environmental conditions (Kappes et al. 2011; Boyd et al. 2014). To our knowledge, there has been no robust comparison of the foraging ranges of tropical oceanic seabirds from large and small colonies in similar environments to test whether competition actually results in larger foraging areas, longer foraging trips, higher energy expenditure and ultimately differences in productivity.

Competition for food resources may also lead to increased intra-specific niche segregation to enable individuals to reduce competition with conspecifics. Individual specialisation is widely known to have fitness consequences (Bolnick et al. 2003; Alves et al. 2013), and there is growing appreciation of individual differences in foraging strategies of seabirds (Kubetzki et al. 2009; Oppel et al. 2009; Sommerfeld et al. 2013b). In temperate seabirds, individuals have been found to specialise on particular environments or locations (Woo et al. 2008; Votier et al. 2010; Patrick et al. 2014), but in tropical environments, where prey is generally spatially less predictable, it may not be profitable for individuals to consistently search or exploit the same areas at sea (Weimerskirch et al. 2005; Hennicke and Weimerskirch 2014; Sommerfeld et al. 2015). We hypothesised that on tropical islands with higher seabird density, and thus more intense competition, individuals would exhibit less consistency in foraging trip characteristics than on an island with lower levels of competition, because productive prey patches would be exploited more rapidly and would therefore be less likely to still exist on a subsequent foraging trip.

In this study, we examined whether the foraging distribution and breeding success of a common tropical seabird on two South Atlantic islands that differ in the size of their seabird colonies (Stonehouse 1962) are consistent with Ashmole's hypothesis. Ascension Island supports approximately one million nesting seabirds of 11 different species, while the similar island of St. Helena has a much smaller seabird community comprising only 8 extant species (4 species have become extinct, likely due to introduced predators) with a seabird population of $\sim 15,000$ birds. Given that the number of seabirds breeding on Ascension is about 2 orders of magnitude larger than on St. Helena, we hypothesised that competition for prey around Ascension would be more intense than around St. Helena and that seabirds on Ascension would 
travel farther than on St. Helena to obtain food for reproduction and, therefore, suffer fitness consequences in having lower breeding success. We tested these predictions with masked booby Sula dactylatra, a widespread pan-tropical species that breeds on both islands and has an apparently high plasticity in foraging strategies (Weimerskirch et al. 2008; Kappes et al. 2011; Sommerfeld et al. 2013a) making it an ideal species to test predictions of Ashmole's hypothesis.

We used GPS tracking on both Ascension and St. Helena to examine whether the foraging trips of breeding masked boobies are longer on Ascension, and whether birds use a larger area for foraging, and have higher energy expenditure due to increased flight costs. We further examined whether individual consistency and breeding success are lower on the island supporting the larger seabird community. This study therefore contributes to a better understanding of the potential mechanisms that affect the fitness consequences of variations in avian colony size.

\section{Methods}

\section{Study area}

We studied masked boobies in a colony on the eastern tip of Ascension Island $\left(14^{\circ} 18^{\prime} \mathrm{W}, 7^{\circ} 56^{\prime} \mathrm{S}\right)$, and in a colony on steep and exposed ridges near the southwestern coast of St. Helena $\left(5^{\circ} 43^{\prime} \mathrm{W}, 16^{\circ} 00^{\prime} \mathrm{S}\right)$. Both islands are of volcanic origin and rise to $>800 \mathrm{~m}$ above sea level, and most seabirds generally avoid the interior of both islands. The islands are situated in deep oligotrophic waters without continental shelves (Fig. 1 and Electronic supplementary material) or current systems that could function as predictable foraging areas with permanently high productivity and prey availability for seabirds. The chlorophyll $a$ concentration in the waters around Ascension was $0.08 \mathrm{mg} / \mathrm{m}^{3}$ during the course of our study, while it was $0.07 \mathrm{mg} / \mathrm{m}^{3}$ on St. Helena (data extracted via movebank.org; Dodge et al. 2013), and the gradients of both chlorophyll $a$ and sea surface temperature did not differ around the two islands (Electronic supplementary material). Commercial tuna fishery occurs in the tropical Atlantic, but the intensity of fishing effort is roughly similar in the waters surrounding Ascension and St. Helena (Tuck et al. 2011; Yeh et al. 2013); hence, there is no a priori reason to believe that differences in productivity or fishing effort would lead to major differences in prey availability around either island.

Ashmole (1963b) cautioned that his hypothesis applied to stable populations in a natural state, but neither St. Helena nor Ascension can be considered in a 'natural state' (Ashmole 1963a; Hilton and Cuthbert 2010). Both on Ascension and St. Helena, the introduction of non-native predators has dramatically reduced seabird population sizes in the past. On St. Helena, feral cats (Felis catus) are widespread, whereas feral

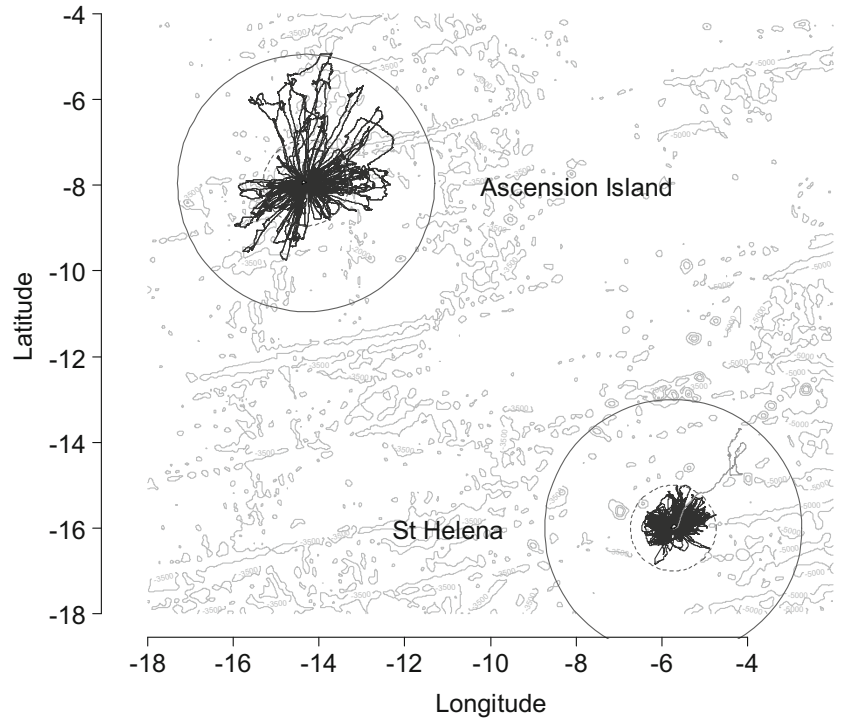

Fig. 1 Foraging trips of masked booby Sula dactylatra recorded with GPS loggers on Ascension Island and St. Helena in 2013 and 2014. Circles represent radii of $100 \mathrm{~km}$ (broken line) and $300 \mathrm{~km}$ (solid line) from the breeding colony. Bathymetry contours represent 500, 3500 and $5000 \mathrm{~m}$ isopleths. Note that the single very long foraging trip (in dark grey) from St. Helena may have occurred after nest failure, as the GPS logger was recovered 4 months after deployment

cats were eradicated from Ascension in 2004 (Ratcliffe et al. 2010). However, masked boobies on St. Helena do not appear to experience high levels of cat predation (Bolton et al. 2011), while seabird chicks on Ascension are exposed to some predation risk by Ascension frigatebirds (Fregata aquila), which are absent from St. Helena. Hence, some predation risk exists on both islands, which may affect the current size of seabird colonies but is unlikely to affect the main foraging patterns and productivity to a greater extent than the mechanisms that Ashmole proposed due to the large difference in the size of the seabird breeding populations: At the time of our study, approximately 4600 masked boobies, 20,000 Ascension frigatebirds (Ratcliffe et al. 2008), 50 red-footed boobies (Sula sula), 500 brown boobies (Sula leucogaster), 100 tropicbirds (Phaeton sp.) and a very large number $(>800,000)$ of terns and noddies nested on Ascension and adjacent rock stacks (Ashmole et al. 1994; Hughes et al. 2008; Ratcliffe et al. 2010). By contrast, there were about 500 masked boobies, 1000 fairy terns (Sternula nereis), 5000 black noddies (Anous minutus), 1000 brown noddies (Anous stolidus), 5000 Madeiran storm petrels (Oceanodroma castro) and smaller numbers of other terns, boobies and tropicbirds nesting on St. Helena and adjacent rocks in 2013 and 2014 (Rowlands et al. 1998; Oppel et al. 2012). Given that boobies and frigatebirds consume similar prey (Dorward 1962; Stonehouse 1963b), while the remaining species consume generally smaller prey, the number of potential food competitors in the masked booby foraging guild was roughly 25,150 on Ascension versus 500 on St. Helena. Breeding on both islands 
is not strictly synchronous or seasonal, and birds can be found at different stages of the breeding cycle at any time of the year (Dorward 1962; Stonehouse 1963a).

\section{Bird capture and tracking}

To describe foraging movements of masked boobies, we captured birds by hand or a noose-pole on the nest in November 2011 (Ascension, $n=15$ ), February and March 2013 (Ascension, $n=27$ ), January 2014 (St. Helena, $n=64$ ) and March 2014 (Ascension, $n=11$ ). We captured birds that were either incubating or attending chicks to facilitate recapture and retrieval of GPS loggers (see Table 1 for number of individuals). We tracked all birds with GPS loggers (iGot-U GT-120, Mobile Action Technology, Taiwan) attached to the base of three or four central tail feathers using Tesa tape. GPS loggers were scheduled to provide a location fix every $100 \mathrm{~s}$ and were sealed in heat-shrink tube for waterproofing prior to deployment. Eggs or chicks were sheltered from the sun while adults were handled to avoid offspring loss due to sun exposure. The weight of the logger with the waterproof sealing was $\sim 20 \mathrm{~g}(1-$ $1.5 \%$ of body mass) and thus well below the threshold associated with adverse impacts (Phillips et al. 2003). All birds were handled for $<20 \mathrm{~min}$ and returned to their nest upon release. Loggers were deployed for 5-8 days to ensure that at least one foraging trip was recorded. We weighed birds upon first capture (prior to being equipped with a logger) and at recapture (after foraging with an attached logger) to assess whether birds maintained or lost body mass. We concluded that loggers did not adversely affect foraging of tracked birds if body mass after logger attachment did not significantly differ from body mass at first capture. Permission to capture and tag birds was granted by the Environmental Management
Directorate on St. Helena, and the Conservation Department of the Ascension Island Government. The attachment of GPS devices met the ethical guidelines of the Special Methods Panel of the British Trust for Ornithology.

\section{GPS data processing and analysis of trip characteristics}

We downloaded GPS data using @trip software (Mobile Action Technology, Taiwan) and processed location data using customised $\mathrm{R}$ scripts to exclude locations around the colony and extract location data associated with foraging trips. For each individual bird, a foraging trip was defined to last $>1.5 \mathrm{~h}$ and extend $>5 \mathrm{~km}$ from the colony (Weimerskirch et al. 2008, 2009), and locations near the colony were removed from analysis.

We first calculated descriptive metrics for each foraging trip and then used generalized linear mixed models (GLMMs) to assess whether the overall foraging strategy of masked boobies differed between the two islands. We used the total trip duration, the minimum path length (trip distance) calculated as the sum of all step lengths between subsequent locations, and the maximum distance to the colony to characterise foraging trips. We also calculated the direction of foraging trips as the great circle route bearing between the colony and the point furthest from the colony (Weimerskirch et al. 2008). As none of the foraging trip characteristics investigated varied with sex (GLMM, all $p>0.1, n=185$ trips for males, and 151 for females), data from males and females were pooled for comparisons between islands (Weimerskirch et al. 2009; Kappes et al. 2011; Sommerfeld et al. 2013b). Because most individuals contributed more than one foraging trip to the data set, and these foraging trips occurred during the same deployment in succession, we accounted for serial
Table 1 Foraging trip characteristics (mean $\pm \mathrm{SD}$ ) of masked boobies tracked with GPS loggers from two islands in the South Atlantic Ocean in 2013 and 2014

\begin{tabular}{|c|c|c|c|c|}
\hline \multirow{2}{*}{$\begin{array}{l}\text { Island } \\
\text { Breeding stage }\end{array}$} & \multicolumn{2}{|l|}{ Ascension } & \multicolumn{2}{|l|}{ St. Helena } \\
\hline & Incubation & Chick & Incubation & Chick \\
\hline$n$ (individual) & 37 & 10 & 25 & 39 \\
\hline$n$ (trips) & 62 & 38 & 91 & 178 \\
\hline trips per day & 0.37 & 0.70 & 0.77 & 0.98 \\
\hline$n$ (overnight trips) & 22 & 4 & 1 & 1 \\
\hline Maximum distance from colony $(\mathrm{km})$ & $139 \pm 76$ & $78 \pm 48$ & $52 \pm 41$ & $41 \pm 24$ \\
\hline Total trip distance $(\mathrm{km})$ & $360 \pm 249$ & $199 \pm 123$ & $160 \pm 226$ & $118 \pm 103$ \\
\hline Total trip duration (h) & $23.9 \pm 22.4$ & $11.4 \pm 8.2$ & $5.8 \pm 6.6$ & $3.4 \pm 2.4$ \\
\hline 'Travelling' time per trip (h) & $6.4 \pm 4.4$ & $3.3 \pm 2.6$ & $2.3 \pm 1.8$ & $1.8 \pm 1.4$ \\
\hline 'Resting' time per trip (h) & $11.5 \pm 14.8$ & $4.1 \pm 4.4$ & $1.7 \pm 3.7$ & $0.4 \pm 0.8$ \\
\hline 'Foraging' time per trip (h) & $6.0 \pm 4.2$ & $4.0 \pm 2.1$ & $1.8 \pm 1.5$ & $1.2 \pm 0.7$ \\
\hline Foraging bouts per trip & $38.2 \pm 34.3$ & $28.4 \pm 15.5$ & $17.0 \pm 12.9$ & $8.2 \pm 5.6$ \\
\hline Duration of each foraging bout (min) & $10.0 \pm 5.6$ & $8.9 \pm 3.9$ & $10.1 \pm 8.5$ & $13.3 \pm 11.7$ \\
\hline
\end{tabular}

"Foraging bout" refers to an uninterrupted sequence of uniform behaviour identified using a hidden Markov model and inferred to represent foraging behaviour 
autocorrelation at the individual level by including individual identity as random intercepts in each model (Bolker et al. 2009). We also included 'breeding stage' as a fixed effect in all models because seabirds are known to employ different foraging strategies during incubation and chick rearing (Weimerskirch et al. 1993; Charrassin et al. 1998; Sommerfeld and Hennicke 2010), and 'tracking season' as a random factor to account for the possibility that foraging distances may have varied during the different time periods when we tracked birds. We fitted all models by the Laplace approximation in R 3.1.0 (R Development Core Team 2014) with the package 'Ime4' using the following generic formula: Imer(trip characteristic $\sim$ island + breeding stage $+(1 \mid$ season/individual $)$ ). For each foraging trip characteristic, we constructed two models: one containing 'island' as fixed effect, and a nested model without the 'island' effect but with the same fixed breeding stage and random effects. To assess whether trip characteristics varied between islands, we compared the two models using a likelihood ratio test (Lewis et al. 2011) and concluded that island was a significant predictor if $p<0.05$. For all analyses, we report the estimated effect size of the response variable as both a mean absolute parameter estimate ( \pm standard error) and as a proportion in relation to the mean value of the respective trip characteristic for the island with the larger mean value.

Repeated trips by the same individuals offer the opportunity to assess within-population flexibility in foraging strategies (Patrick et al. 2014). We used repeated trips by individuals to examine whether individual consistency in foraging trips was more pronounced on St. Helena than on Ascension. We quantified individual consistency by estimating the repeatability for trip duration, trip distance, maximum distance from colony, and foraging direction. We used the R package ' $r p t R$ ' (Nakagawa and Schielzeth 2010) to test whether betweenindividual variance was equal to or smaller than withinindividual variance. Repeatability of foraging directions were calculated using the output of a circular ANOVA and formula provided by Lessells and Boag (1987). We obtained more trips per individual from St. Helena than from Ascension (see the "Results" section), and this unequal sample size may have affected the repeatability estimates. In a second step, we therefore subsampled the St. Helena dataset to use an equal number of trips per individual as in the Ascension dataset, and recalculated repeatabilities. We performed this subsampling 100 times and report the mean repeatability and $95 \%$ confidence intervals for these 100 simulations.

\section{Definition of foraging behaviour and size of foraging area}

To identify foraging locations, we used the instantaneous speed and turning angle between two subsequent locations for a given trip in a hidden Markov model (Patterson et al. 2009; Dean et al. 2012; Langrock et al. 2012), which has been shown to be highly accurate in a comparison of different techniques to classify behaviour from tracking data (Dragon et al. 2012; Beyer et al. 2013). Based on other booby tracking studies, we expected that three distinct behavioural modes would be present during trips and therefore fitted the hidden Markov model (HMM) with three states (Boyd et al. 2014). Among these behavioural modes, we expected that directional travel (commuting to and from foraging areas) would exhibit high speeds and low variation in turning angles, foraging would be characterised by intermediate speeds and high variance in turning angles, and roosting on the water would be indicated by very low speeds (Sommerfeld et al. 2013a; Boyd et al. 2014). Because boobies rely on visual cues to identify and capture prey (Nelson 1978), they are extremely unlikely to forage at night and have been found to spend nights resting on the water when tracked with accelerometers and time depth recorders (Sommerfeld et al. 2013b; Hennicke and Weimerskirch 2014). We therefore excluded all nocturnal instances where the HMM identified behaviour consistent with 'foraging' from analyses of foraging range and behaviour.

We defined a 'foraging bout' as a sequence of consecutive locations that were assigned to the same behavioural mode (foraging) by the HMM and were separated from previous or subsequent bouts of the same behavioural mode by at least two locations in a different behavioural mode.

To assess whether the size of foraging areas differed between islands, we used a kernel analysis to estimate the utilisation distribution of foraging bouts for masked boobies from each island implemented in $\mathrm{R}$ with the package 'adehabitatHR' (Calenge 2011). Kernel analysis requires the definition of a smoothing parameter, which can be informed by the radius of area-restricted search (Pinaud and Weimerskirch 2005). Because area-restricted search radii differed between masked booby populations in previous tracking studies (Weimerskirch et al. 2008; Kappes et al. 2011; Sommerfeld et al. 2013a), we estimated the scale of the area-restricted search following Pinaud and Weimerskirch (2005) and used this radius as smoothing parameter in our kernel analysis. We then examined whether general $(95 \%)$ and core $(50 \%)$ foraging areas at sea were larger for masked boobies from Ascension than from St. Helena.

\section{Calculation of energy expenditure}

Birds nesting in larger colonies can have lower productivity if they have to expend more energy for foraging and can therefore deliver less energy to offspring (Ballance et al. 2009). We tested whether energy expenditure on Ascension was higher than on St. Helena by using the behavioural classification of our HMM to calculate the amount of time spent flying and resting, and we assumed that energy expenditure of foraging and directional travel was similar (Boyd et al. 2014). We then used allometric equations derived from similar species whose 
energy expenditure was measured in the field using the doubly labelled water technique, and calculated the energy spent in flight and during resting on land or on water following the same approach as previous studies (Birt-Friesen et al. 1989; Weimerskirch et al. 2008; Boyd et al. 2014). Because body mass was not available for all individuals, we used the mean body mass of $1424 \mathrm{~g}$ for males and $1666 \mathrm{~g}$ for females to estimate energy expenditure of 94.4 or $106.1 \mathrm{~kJ} / \mathrm{h}$ during flight and 36.6 and $41.1 \mathrm{~kJ} / \mathrm{h}$ during rest for males and females, respectively. We then calculated the total energy expenditure for each individual throughout the entire tag deployment time based on the proportion of time spent in different activities as derived from the HMM, and assuming that birds rested at the nest if they were not foraging at sea. We divided the total energy expenditure by the duration of the deployment interval and calculated the daily energy expenditure for each individual. We then used a GLMM similar to those described for trip characteristics to test whether daily energy expenditure differed between islands, while accounting for differences between sexes, breeding stages, and random variation among individuals.

\section{Nest monitoring}

To test whether productivity on Ascension was lower than on St. Helena, we monitored $>150$ masked booby nests on each island between 2012 and 2014. Masked boobies generally lay two eggs but raise only one fledgling due to nearobligate siblicide, and an increase in productivity usually results from an increase in the proportion of nests that produce a fledgling (Nelson 1978; Anderson 1990a, 1990b). On both of our study islands, masked boobies nest in unvegetated open terrain and their nests were very easy to detect and monitor. We marked nests during the incubation phase and visited nests once every 1-3 weeks to assess fledging success. Nest failure was assumed if a nest was found empty and if no chicks of appropriate age were encountered in the vicinity of the nest location, and we considered nests as 'fledged' if a fully grown young bird could be unambiguously assigned to a nest. We excluded 47 of originally 217 nests on Ascension where the fate of chicks could not be ascertained due to mingling of chicks of adjacent nests. For each island, we estimated the daily nest survival rate corrected for the exposure time of nests to account for nests being discovered at various stages (Mayfield 1975). We tested for differences in productivity between islands using a logistic exposure GLMM with 'year' as a random effect to account for environmental stochasticity among years (Shaffer 2004). We report nest survival probability as the daily survival probability raised to the power of 164, which is the average length of the nesting period for masked boobies (Dorward 1962; Nelson 1978).

\section{Results}

\section{Effects of tag attachment}

On St. Helena, we deployed 64 GPS loggers and retrieved 62 (97\%), while on Ascension, we deployed 53 and retrieved 48 (91\%, Table 1). Masked boobies weighed on average $1540 \mathrm{~g}$ $( \pm 190 \mathrm{~g})$ at first capture, and $1550 \mathrm{~g}( \pm 200 \mathrm{~g})$ when loggers were retrieved, and there was no detectable mass loss during the deployment period (paired $t$ test $t=-0.85, n=48, p=0.40$ ). In addition, nest monitoring after GPS deployment and recovery indicated no nest failure among the nests that were monitored for 1.5 months after adult birds had been tracked. We therefore concluded that GPS logger attachment did not affect the foraging ability of masked boobies.

\section{Foraging trip characteristics and size of foraging area}

We recorded a total of 369 foraging trips of masked boobies, 269 from St. Helena and 100 from Ascension. The larger number of foraging trips on St. Helena occurred because masked boobies on St. Helena conducted on average $0.36 \pm$ 0.06 foraging trips more per day than birds on Ascension ( $t=$ 5.7, $p<0.001$; Table 1).

Foraging trips undertaken by birds tagged on Ascension were on average longer in both time and distance and extended further from the colony than those made by birds tagged on St. Helena (Fig. 1 and Table 1). After accounting for differences between breeding stages (incubation, chick rearing), seasons and repeat trips of individuals, foraging trips from St. Helena were on average $64 \mathrm{~km}(46 \%)$ closer to the colony than those from Ascension (likelihood ratio test $\chi^{2}{ }_{7}=9.85$, $p=0.002$, Table 1). Likewise, trip length was on average $221 \mathrm{~km}(61 \%)$ shorter on St. Helena $\left(\chi^{2}{ }_{7}=9.51, p=0.002\right.$; Table 1), and trip duration was on average $18.0 \mathrm{~h}$ (75\%) shorter $\left(\chi^{2}{ }_{7}=7.96, p=0.005\right.$; Table 1 and Fig. 2$)$. The only trip from St. Helena that reached $>120 \mathrm{~km}$ from the colony was recorded during pilot work in August 2013, but the tracked individual may have lost its nest before the long trip was recorded (the GPS logger was retrieved 4 months later), and this trip was excluded from analysis (but is shown in Fig. 1 for reference).

Birds set off in all directions from both islands. On Ascension, the most frequent directions were to the NNE ( $21 \%$ of trips) and to the SSE ( $26 \%$ of trips), whereas on St. Helena, the mean foraging direction was to the ENE ( $35 \%$ of trips). Thus, there was a significant difference in the mean foraging direction between the two islands $\left(\mathrm{F}_{1,367}=50.84\right.$, $p<0.001$ ), which may have been partly a result of the location of the colony on the respective island.

The hidden Markov model distinguished three discrete behavioural modes during masked booby trips, and we inferred that the behavioural mode with intermediate speeds and high 
Fig. 2 Relationship between foraging trip duration and maximum distance from the colony of masked booby Sula dactylatra tracked with GPS loggers from colonies on Ascension Island and St. Helena. All trips $>20 \mathrm{~h}$ in duration were considered as overnight trips (Table 1)

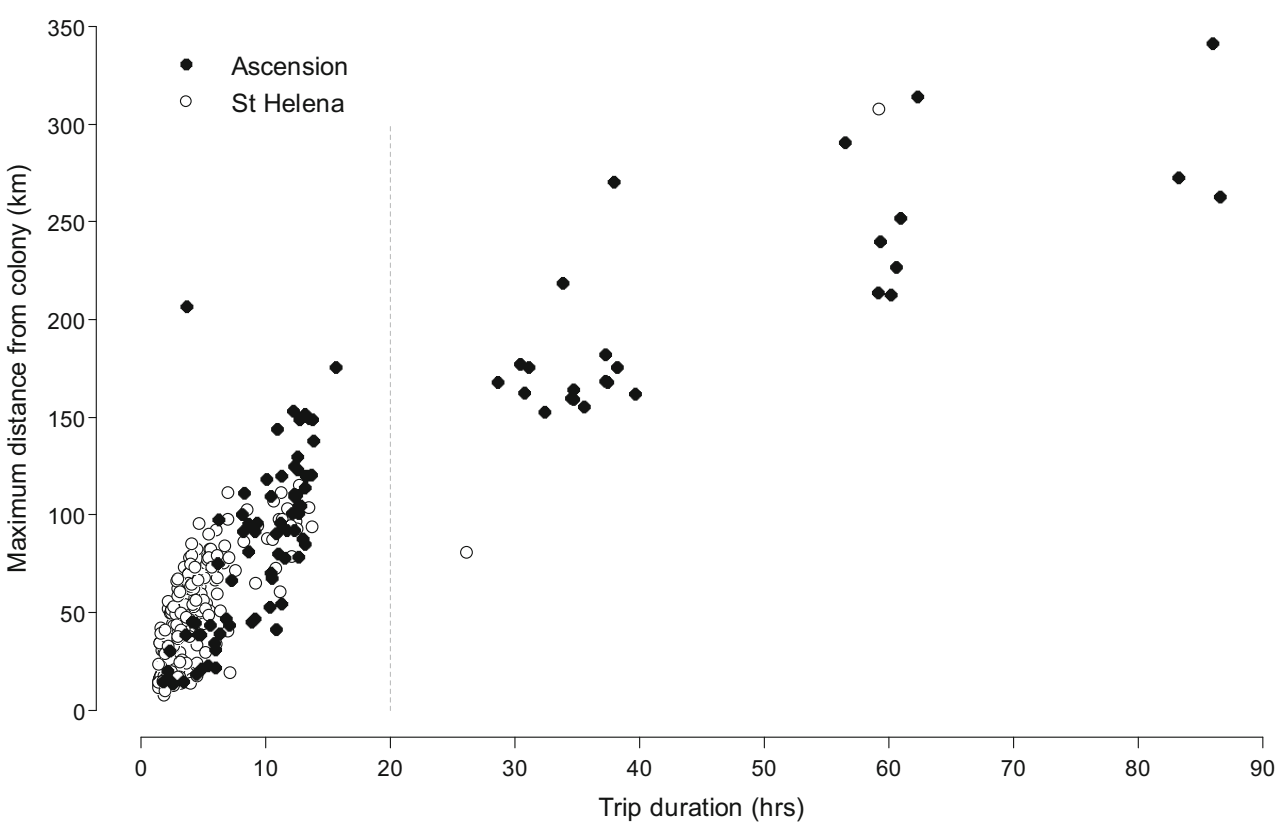

variation in turning angles reflected restricted area search behaviour and thus the typical movement associated with foraging in pelagic seabirds (Table 2). Using this behavioural classification, foraging trips of masked boobies from St. Helena included on average $\sim 50 \%$ fewer foraging bouts than trips from Ascension (likelihood ratio test $\chi^{2}{ }_{7}=15.6, p<0.001$, Table 1). However, the length of each discrete foraging bout was on average $\sim 10 \mathrm{~min}$ and did not differ between the two islands $\left(\chi_{7}^{2}=0.048, p=0.83\right.$; Table 1$)$. Likewise, the proportion of time spent in the behavioural mode of 'foraging' did not differ between islands $\left(\chi^{2}{ }_{7}=0.34, p=0.56\right)$, but because trips were longer from Ascension the amount of time spent foraging per trip was larger on Ascension than on St. Helena (Table 1). Masked boobies on St. Helena had very few overnight trips and therefore spent a higher proportion of their trips travelling $\left(\chi^{2}{ }_{7}=11.7, p<0.001\right.$; Table 1$)$, while birds from Ascension spent a higher proportion of their trips resting as a consequence of frequently spending the night at sea $\left(\chi_{7}^{2}=8.3, p=0.004\right.$; Table 1$)$.

Due to their longer foraging trips, birds on Ascension spent more time flying than birds on St. Helena (Table 1), and their daily energy expenditure was therefore greater for both sexes and both breeding stages $\left(\chi^{2}=15.8, p<0.001\right.$, Fig. 3$)$.

Table 2 Speed (mean \pm SD) and variance of turning angles of three discrete behavioural modes identified with a hidden Markov model in masked booby foraging trips from two islands in the South Atlantic Ocean in 2013 and 2014

\begin{tabular}{lll}
\hline Inferred behaviour & Speed $(\mathrm{m} / \mathrm{s})$ & Variance in turning angle $\left({ }^{\circ}\right)$ \\
\hline Resting & $0.34 \pm 0.17$ & 71.6 \\
Foraging & $4.46 \pm 3.25$ & 126.2 \\
Travelling & $12.78 \pm 3.49$ & 3.9 \\
\hline
\end{tabular}

The radius of area-restricted search behaviour derived from first passage time was $6.25 \mathrm{~km}$. Using only the locations classified as foraging behaviour, and a smoothing parameter of $6.25 \mathrm{~km}$, the size of the $50 \%$ kernel utilisation distribution (UD) of foraging locations around Ascension was $18,707 \mathrm{~km}^{2}$ and thus almost an order of magnitude larger than the $50 \%$ UD of foraging locations around St. Helena $\left(1983 \mathrm{~km}^{2}\right)$. Likewise, the $95 \%$ UD of foraging locations on Ascension $\left(79,085 \mathrm{~km}^{2}\right)$ was several times larger than around St. Helena $\left(19,404 \mathrm{~km}^{2}\right)$. Thus, the area used by masked boobies for foraging covered $17.9 \%$ of the exclusive economic zone of Ascension $\left(441,658 \mathrm{~km}^{2}\right)$, but only $4.4 \%$ of the exclusive economic zone of St. Helena $\left(444,916 \mathrm{~km}^{2}\right)$.

\section{Individual foraging consistency}

We obtained an average of 2 (range 1-4) foraging trips from individual masked boobies on Ascension, and 4 trips (1-10) from individuals on St. Helena, with 88 of the 110 tracked individuals performing $>1$ trip during the deployment period ( $n=60$ on St. Helena, $n=28$ on Ascension). On both islands, masked boobies showed high individual repeatability in trip duration (Ascension, $r=0.63,95 \%$ confidence interval $0.46-$ $0.80, p=0.002$; St. Helena, $r=0.71,0.62-0.80, p=0.001)$ and moderate repeatability in the maximum distance from the colony (Ascension, $r=0.44,0.21-0.66, p=0.02$; St. Helena, $r=0.48,0.35-0.61, p=0.001)$. However, on Ascension, masked boobies also showed high repeatability in the total foraging trip distance $(r=0.52,0.31-0.72, p=0.003)$ and foraging direction $(r=0.69,0.55-0.84, p<0.001)$, while birds on St. Helena had both long and short trips and did not show any repeatability in total trip distance $(r=0.15,0.03-0.27, p=0.07)$ or direction $(r=0.08,0.0-0.19, p=0.14)$. These patterns 
Fig. 3 Estimated daily energy expenditure $( \pm 1$ standard deviation) of male and female masked booby Sula dactylatra during the incubation and chickrearing stage on Ascension Island and St. Helena. Energy expenditure was estimated based on allometric equations and the proportion of time spent flying and resting

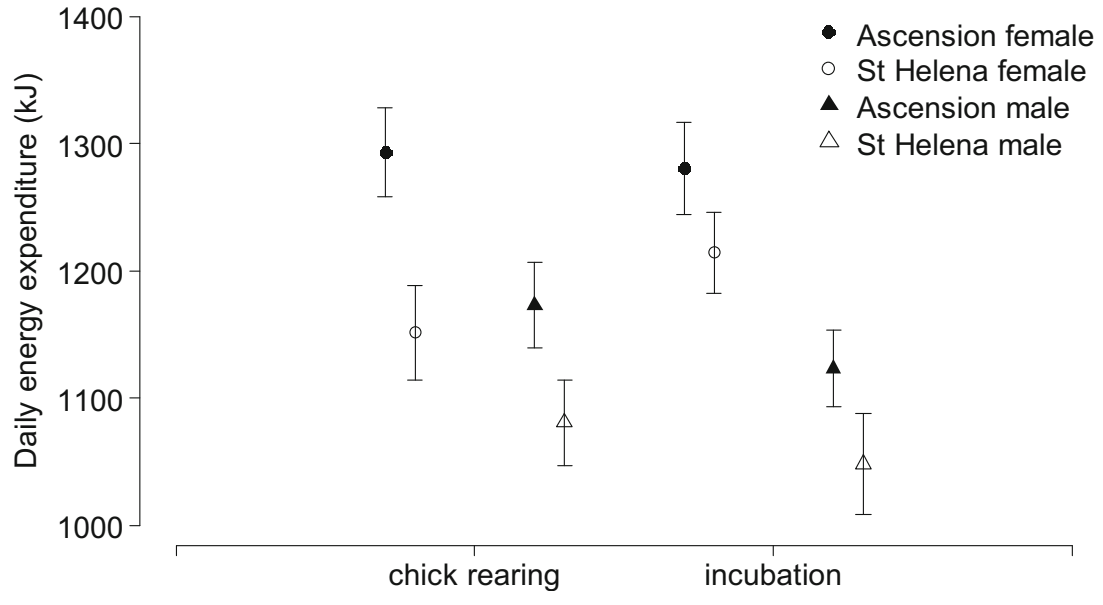

persisted even if we subsampled the St. Helena dataset to the same number of trips per individual as on Ascension, and repeatabilities in those simulations generally decreased (trip duration $r=0.48,0.27-0.70, p=0.06$; maximum distance $r=0.37,0.12-0.62, p=0.02$; total trip distance $r=0.11,0.0$ $0.36, p=0.28$; direction $r=0.11,0.0-0.20, p=0.44)$.

\section{Productivity}

We obtained reliable data on breeding success from 170 nests on Ascension, and 201 nests on St. Helena. Mayfield nest survival was 10 percentage points higher on St. Helena (47\%) than on Ascension (37\%), and the model that included 'island' as a fixed effect was significantly better than the model that assumed that nest survival was equal between the two islands (likelihood ratio test $\chi_{3}^{2}=6.51, p=0.01$ ). We recorded one nest on St. Helena where the pair succeeded in raising two fledglings.

\section{Discussion}

Our study shows that masked boobies breeding on an island with a larger number of potential food competitors exploited a much larger foraging area and conducted longer trips that carried them farther away from the colony than masked boobies breeding on a similar island with a much smaller seabird colony. As a consequence, the birds nesting on the island with the smaller colony expended less energy per day and had higher breeding success. Higher productivity could result in greater population growth rates and ultimately lead to similar colony sizes on both islands if these were in a natural state. This study therefore provides support for a potential mechanism on how differences in avian colony size can affect the fitness of individuals. Our results are fully consistent with the hypothesis that tropical seabird populations are limited by available food resources during the breeding season and that competition for food resources around the colony is greater in larger colonies (Ashmole 1963b).

The area used by foraging masked boobies on Ascension was almost 10 times greater than the area exploited by masked boobies from St. Helena, suggesting that the larger number of seabirds present on Ascension may lead to substantial competition for available prey resources that ultimately necessitates longer foraging trips to explore more distant marine areas where competition is less intense (Lewis et al. 2001; Ainley et al. 2006; Elliott et al. 2009). These longer foraging trips may lead to energetic constraints for individuals, which may ultimately limit the amount of energy provided to chicks and thus affect the reproductive output (Ashmole 1963b; Szostek et al. 2013; Boyd et al. 2014).

Competition among seabirds may be of either exploitative nature, leading to a reduction in the actual abundance of prey items (Birt et al. 1987), or may consist of interference competition where the foraging activity itself limits the access to or availability of prey for other individuals (Lewis et al. 2001). Tropical seabirds obtain their prey generally near the water surface (Diamond 1978), and masked boobies in particular do not perform dives $>6 \mathrm{~m}$ deep (Weimerskirch et al. 2009; Sommerfeld et al. 2013b). The principal mode of foraging for oceanic tropical seabirds is to exploit fish aggregations that are driven to the water surface by large predatory fish or mammals (Ashmole 1971; Diamond 1978; Goyert et al. 2014). On Ascension, in particular, both boobies and frigatebirds appear to principally consume flying fish of the genus Exocoetus, which they obtain near or above the sea surface (Dorward 1962; Stonehouse 1963b). Because many seabirds can gather and forage at such temporarily available food patches, interference competition is the most likely form of competition between tropical seabirds (Weimerskirch et al. 2005; 2007). Thus, not only the number of conspecifics nesting on an island but also other seabird species that forage at near-surface fish schools may interfere with masked boobies and thus partly explain an expanding foraging range to reduce interference competition. 
Tracking seabirds simultaneously on two remote islands is logistically challenging, and it is possible that foraging differences between islands are an artefact of the different times during which birds were tracked (Boyd et al. 2014). Because we tracked birds on Ascension in three different seasons, and accounted for random variability over time in our models, we consider it unlikely that the differences we found were an artefact of the different times at which birds were tracked. Alternatively, the different foraging ranges may have been caused by different baseline prey abundances around the two islands. Prey abundance in the open ocean is extremely difficult to quantify, but the two most widely used proxies of food availability, namely, primary productivity and sea surface temperature, did not indicate systematic differences of productivity during our study (Electronic supplementary material). In fact, Ascension Island was in the past assumed to be in much more productive waters than St. Helena (Stonehouse 1962); hence, it is unlikely that the longer foraging trips on Ascension were caused by lower productivity of the surrounding waters. Prey abundance and availability may be substantially affected by fisheries, and more intense fishery around Ascension may have led to lower prey availability and expanded foraging ranges of birds (Bertrand et al. 2012). While existing data suggest that fishing effort is similar in the waters around Ascension and St. Helena (Tuck et al. 2011; Yeh et al. 2013), it is possible that unassessed local or international fisheries differ between the two islands (Agnew et al. 2009), but the tropical waters around Ascension and St. Helena do not appear to be targeted by major fishing fleets such as the Chinese distant-water fleet (Pauly et al. 2013). We therefore conclude that the different size of the seabird colonies is the most plausible explanation for the differences in foraging behaviour that we found between the two islands.

Masked boobies showed large variability in the length and direction of foraging trips. Much of this variation was due to variation between individuals, a common pattern that has been found in several seabird species (Oppel et al. 2009; Sommerfeld et al. 2013b; Patrick et al. 2014). Contrary to our expectation, birds from Ascension exhibited higher individual repeatability in trip direction and total trip distance than birds from St. Helena. Our simulations showed that this pattern persisted even when we controlled for the fact that birds from Ascension undertook fewer foraging trips than the birds from St. Helena. Boobies are generally believed to forage in the same direction from the colony for several days but may change foraging direction after unsuccessful trips (Anderson and Ricklefs 1987; Weimerskirch et al. 2005). On St. Helena, there was very low repeatability in foraging directions. In the more competitive environment around Ascension, it may be more beneficial to repeatedly exploit 'known' patches than around St. Helena, where birds might have an equal chance to find a productive prey patch in any direction. The high repeatability in total trip distance on Ascension may also indicate that the birds on Ascension are foraging at the limit of their individual physical capability and are not in a position to extend their foraging trips any further. Tropical boobies generally do not engage in long overnight foraging trips (Nelson 1978; Weimerskirch et al. 2008; Hennicke and Weimerskirch 2014), but we found that $35 \%$ of incubation trips and $10.5 \%$ of chick-rearing trips from Ascension included at least one night at sea, whereas such trips were almost absent on St. Helena. Overnight trips presumably facilitate an expansion of the foraging range and are therefore a suitable strategy for birds at the larger colony facing more intense competition. Due to the longer foraging trips, birds from Ascension had higher daily energy expenditure (Fig. 3), which would require them to obtain more food to balance their energy budget. Although we found that the length of foraging bouts were remarkably similar between the two islands and may correspond with the temporal availability of prey near the surface, birds from Ascension spent overall more time foraging owing to a larger number of foraging bouts during their longer trips. Although the higher energy expenditure is partly a consequence of greater foraging effort, it is likely that birds from Ascension need to spend more time and energy on foraging to meet the energetic requirements of their longer foraging trips.

The foraging trips of masked boobies on Ascension were relatively long in comparison to birds tracked from other colonies in the Indian (Kappes et al. 2011) or Pacific Ocean (Weimerskirch et al. 2008; Young et al. 2010; Sommerfeld et al. 2013a). Masked boobies on Ascension undertook foraging trips that were on average $\sim 2.5 \mathrm{~h}$ longer but $\sim 25 \mathrm{~km}$ closer to the colony than birds nesting in a much larger colony in the eastern tropical Pacific (Weimerskirch et al. 2008), where $>110,000$ masked boobies breed (Pitman et al. 2005). While comparisons between different colonies in different oceans are confounded by environmental differences and prey densities (Kappes et al. 2011), the fact that Ascension boobies travel comparatively long distances supports the hypothesis that other species may also interfere with foraging masked boobies. On Ascension in particular, Ascension frigatebirds, as well as the very large number of highly pelagic sooty terns, consume similar prey species as masked boobies, although terns generally consume smaller-sized fish (Dorward 1962; Stonehouse 1963b; Nelson 1978). These species may thus add to the intraspecific competition for available prey, even if only by interference at ephemeral prey patches. Such a pattern is extremely important for the design of marine protected areas: In the absence of colony-specific distribution data, one recommended approach to identify important areas at sea is to use the foraging radius around a colony (BirdLife International 2010; Grecian et al. 2012; Thaxter et al. 2012). While colony size of the target species has been used to adjust the foraging range around each colony (Grecian et al. 2012), indirect interference competition, especially in tropical pelagic species, 
may warrant that the colony sizes of potential competitor species are taken into account when delineating important marine areas based on foraging ranges.

Acknowledgments We appreciate the enthusiastic assistance and advice during data collection from Ian Fisher, Richard Hesketh, Dane Wade, Catherine Supple, Natasha Williams, Kenickie Andrews, Pete Mayhew, Annette Broderick and Brendan Godley, Judith Brown, Phil Lambdon, Shayla Ellick, Dave Higgins, the St. Helena National Trust, and staff in the Environmental Management Division of the Environmental and Natural Resources Directorate on St. Helena. The work on Ascension Island was partly funded by a Darwin Grant (\# 19026) to Ascension Island Government and the University of Exeter (Annette Broderick and Brendan Godley), managed on-island by NW and SW. The work on St. Helena was partly funded by Enterprise St. Helena and the Seabird Group. Nigel Butcher and Andrew Asque assisted with preparation of loggers and equipment. Samantha Patrick, Phil Taylor and Mark Miller generously shared unpublished $\mathrm{R}$ code to analyse tracking data. Three anonymous reviewers, Henri Weimerskirch and Charles Brown provided helpful comments that improved the manuscript.

Ethical Standards This research study was carried out under permission and with collaboration of the Ascension Island Government Conservation Department and the St. Helena Environmental Management Directorate. The capture and handling of birds and attachment of unconventional marks were carried out under licence from the British Trust for Ornithology.

Conflict of interest The authors declare that they have no conflict of interest.

\section{References}

Agnew DJ, Pearce J, Pramod G, Peatman T, Watson R, Beddington JR, Pitcher TJ (2009) Estimating the worldwide extent of illegal fishing. PLoS ONE 4:e4570

Ainley DG, Boekelheide RJ (1983) An ecological comparison of oceanic seabird communities of the South Pacific Ocean. Stud Avian Biol 8: 2-23

Ainley DG, Ford RG, Brown ED, Suryan RM, Irons DB (2003) Prey resources, competition, and geographic structure of kittiwake colonies in Prince William Sound. Ecology 84:709-723

Ainley DG, Ballard G, Dugger KM (2006) Competition among penguins and cetaceans reveals trophic cascades in the western Ross Sea, Antarctica. Ecology 87:2080-2093

Alves JA, Gunnarsson TG, Hayhow DB, Appleton GF, Potts PM, Sutherland WJ, Gill JA (2013) Costs, benefits, and fitness consequences of different migratory strategies. Ecology 94:11-17

Anderson DJ (1990a) Evolution of obligate siblicide in boobies. 1. A test of the insurance-egg hypothesis. Am Nat 135:334-350

Anderson DJ (1990b) Evolution of obligate siblicide in boobies. 2: food limitation and parent-offspring conflict. Evolution 44:2069-2082

Anderson D, Ricklefs R (1987) Radio-tracking masked and blue-footed boobies (Sula spp.) in the Galapagos Islands. Natl Geogr Res 3:152163

Ashmole NP (1963a) The extinct avifauna of St. Helena Island. Ibis 103b: $390-408$

Ashmole NP (1963b) The regulation of numbers of tropical oceanic birds. Ibis 103 b:458-473

Ashmole NP (1971) Seabird ecology and the marine environment. In: Farner DS, King JR (eds) Avian biology. Academic Press, New York, pp 223-286
Ashmole NP, Ashmole MJ, Simmons KEL (1994) Seabird conservation and feral cats on Ascension Island, South Atlantic. In: Nettleship DN, Burger J, Gochfeld M (eds) Seabirds on islands: threats, case studies and action plans. BirdLife International, Cambridge, pp 94 121

Au DW, Pitman RL (1986) Seabird interactions with dolphins and tuna in the eastern tropical Pacific. Condor 88:304-317

Ballance LT, Ainley DG, Ballard G, Barton K (2009) An energetic correlate between colony size and foraging effort in seabirds, an example of the Adelie penguin Pygoscelis adeliae. J Avian Biol 40:279288

Bertrand S, Joo R, Arbulu Smet C, Tremblay Y, Barbraud C, Weimerskirch H (2012) Local depletion by a fishery can affect seabird foraging. J Appl Ecol 49:1168-1177

Beyer HL, Morales JM, Murray D, Fortin M-J (2013) The effectiveness of Bayesian state-space models for estimating behavioural states from movement paths. Methods Ecol Evol 4:433-441

BirdLife International (2010) Marine important bird areas toolkit: standardised techniques for identifying priority sites for the conservation of seabirds at-sea. BirdLife International, Cambridge

Birt V, Birt T, Goulet D, Cairns D, Montevecchi W (1987) Ashmole's halo: direct evidence for prey depletion by a seabird. Mar Ecol Prog Ser 40:205-208

Birt-Friesen VL, Montevecchi WA, Cairns D, Macko SA (1989) Activity-specific metabolic rates of free-living Northern Gannets and other seabirds. Ecology 70:357-367

Bolker BM, Brooks ME, Clark CJ, Geange SW, Poulsen JR, Stevens MHH, White J-SS (2009) Generalized linear mixed models: a practical guide for ecology and evolution. Trends Ecol Evol 24:127-135

Bolnick DI, Svanbäck R, Fordyce JA, Yang LH, Davis JM, Hulsey CD, Forister ML (2003) The ecology of individuals: incidence and implications of individual specialization. Am Nat 161:1-28

Bolton M, Watt REF, Henry L, Clingham E (2011) Re-colonisation and successful breeding of Masked Boobies Sula dactylatra on mainland St Helena, South Atlantic, in the presence of Feral Cats Felis catus. Seabirds 24:60-71

Boyd C, Punt AE, Weimerskirch H, Bertrand S (2014) Movement models provide insights into variation in the foraging effort of central place foragers. Ecol Model 286:13-25

Brown CR, Brown MB (1996) Coloniality in the cliff swallow: the effect of group size on social behavior. University Chicago Press, Chicago

Brown CR, Brown MB (2001) Avian coloniality. Curr Ornithol 16:1-82

Brown CR, Brown MB, Roche EA (2013) Spatial and temporal unpredictability of colony size in cliff swallows across 30 years. Ecol Monogr 83:511-530

Burger AE, Shaffer SA (2008) Application of tracking and data-logging technology in research and conservation of seabirds. Auk 125:253264

Calenge C (2011) Home range estimation in R: the adehabitatHR package. $\mathrm{R}$ package version 0.4.4. The Comprehensive $\mathrm{R}$ Archive Network, http://cran.r-project.org/web/packages/adehabitatHR/ index.html

Charrassin J-B, Bost C, Pütz K, Lage J, Dahier T, Zorn T, le Maho Y (1998) Foraging strategies of incubating and brooding king penguins Aptenodytes patagonicus. Oecologia 114:194-201

Danchin E, Wagner RH (1997) The evolution of coloniality: the emergence of new perspectives. Trends Ecol Evol 12:342-347

Dean B, Freeman R, Kirk H, Leonard K, Phillips RA, Perrins CM, Guilford T (2012) Behavioural mapping of a pelagic seabird: combining multiple sensors and a hidden Markov model reveals the distribution of at-sea behaviour. J R Soc Interface 10:1-8

Diamond AW (1978) Feeding strategies and population size in tropical seabirds. Am Nat 112:215-223

Dodge S, Bohrer G, Weinzierl R, Davidson S, Kays R, Douglas D, Cruz S, Han J, Brandes D, Wikelski M (2013) The environmental-data 
automated track annotation (Env-DATA) system: linking animal tracks with environmental data. Mov Ecol 1:3

Dorward D (1962) Comparative biology of the white booby and the brown booby Sula spp. at Ascension. Ibis 103:174-220

Dragon A, Bar-Hen A, Monestiez P, Guinet C (2012) Comparative analysis of methods for inferring successful foraging areas from Argos and GPS tracking data. Mar Ecol Prog Ser 452:253-267

Elliott KH, Woo KJ, Gaston AJ, Benvenuti S, Dall'Antonia L, Davoren GK (2009) Central-place foraging in an Arctic seabird provides evidence for Storer-Ashmole's halo. Auk 126:613-625

Gaston AJ, Ydenberg RC, Smith GJ (2007) Ashmole's halo and population regulation in seabirds. Mar Ornithol 35:119-126

Goyert HF, Manne LL, Veit RR (2014) Facilitative interactions among the pelagic community of temperate migratory terns, tunas and dolphins. Oikos 123:1400-1408

Grecian WJ, Witt MJ, Attrill MJ, Bearhop S, Godley BJ, Grémillet D, Hamer KC, Votier SC (2012) A novel projection technique to identify important at-sea areas for seabird conservation: an example using Northern gannets breeding in the North East Atlantic. Biol Conserv 156:43-52

Hebblewhite M, Haydon DT (2010) Distinguishing technology from biology: a critical review of the use of GPS telemetry data in ecology. Philos T Roy Soc B 365:2303-2312

Hennicke JC, Weimerskirch H (2014) Coping with variable and oligotrophic tropical waters: foraging behaviour and flexibility of the Abbott's booby Papasula abbotti. Mar Ecol Prog Ser 499:259-273

Hilton GM, Cuthbert R (2010) The catastrophic impact of invasive mammalian predators on birds of the UK Overseas Territories: a review and synthesis. Ibis 152:443-458

Hughes BJ, Martin GR, Reynolds SJ (2008) Cats and seabirds: effects of feral domestic cat Felis silvestris catus eradication on the population of Sooty Terns Onychoprion fuscata on Ascension Island, South Atlantic. Ibis 150:122-131

Kappes MA, Weimerskirch H, Pinaud D, le Corre M (2011) Variability of resource partitioning in sympatric tropical boobies. Mar Ecol Prog Ser 441:281-294

Kubetzki U, Garthe S, Fifield D, Mendel B, Furness RW (2009) Individual migratory schedules and wintering areas of northern gannets. Mar Ecol Prog Ser 391:257-265

Langrock R, King R, Matthiopoulos J, Thomas L, Fortin D, Morales JM (2012) Flexible and practical modeling of animal telemetry data: hidden Markov models and extensions. Ecology 93:2336-2342

Lessells C, Boag PT (1987) Unrepeatable repeatabilities: a common mistake. Auk 104:116-121

Lewis S, Sherratt T, Hamer K, Wanless S (2001) Evidence of intraspecific competition for food in a pelagic seabird. Nature 412 : 816-819

Lewis F, Butler A, Gilbert L (2011) A unified approach to model selection using the likelihood ratio test. Methods Ecol Evol 2:155-162

Mayfield HF (1975) Suggestions for calculating nest success. Wilson Bull 87:456-466

Nakagawa S, Schielzeth H (2010) Repeatability for Gaussian and nonGaussian data: a practical guide for biologists. Biol Rev 85:935-956

Nelson JB (1978) The Sulidae: gannets and boobies. Oxford University Press, Oxford

Oppel S, Powell AN, Dickson DL (2009) Using an algorithmic model to reveal individually variable movement decisions in a wintering sea duck. J Anim Ecol 78:524-531

Oppel S, Burns F, Ellick G, George K, Beard A, Henry L, Clingham E, Hillman JC, Hollins JD, Thorsen MJ (2012) Recent observations suggest Bulwer's Petrel Bulweria bulwerii might breed on St Helena. Mar Ornithol 40:67-68

Patrick SC, Bearhop S, Grémillet D, Lescroël A, Grecian WJ, Bodey TW, Hamer KC, Wakefield E, le Nuz M, Votier SC (2014) Individual differences in searching behaviour and spatial foraging consistency in a central place marine predator. Oikos 123:33-40
Patterson TA, Basson M, Bravington MV, Gunn JS (2009) Classifying movement behaviour in relation to environmental conditions using hidden Markov models. J Anim Ecol 78:1113-1123

Pauly D, Belhabib D, Blomeyer R et al (2013) China's distant-water fisheries in the 21st century. Fish Fish 15:474-488

Phillips RA, Xavier JC, Croxall JP (2003) Effects of satellite transmitters on albatrosses and petrels. Auk 120:1082-1090

Pinaud D, Weimerskirch H (2005) Scale-dependent habitat use in a longranging central place predator. J Anim Ecol 74:852-863

Pitman RL, Ballance LT, Bost C (2005) Clipperton Island: pig sty, rat hole and booby prize. Mar Ornithol 33:193-194

Ratcliffe N, Pelembe T, White R (2008) Resolving the population status of Ascension frigatebird Fregata aquila using a 'virtual ecologist'model. Ibis 150:300-306

Ratcliffe N, Bell MB, Pelembe T, Boyle D, Benjamin R, White R, Godley BJ, Stevenson J, Sanders S (2010) The eradication of feral cats from Ascension Island and its subsequent recolonization by seabirds. Oryx 44:20-29

Rowlands BW, Trueman T, Olson SL, McCulloch MN, Brooke RK (1998) The Birds of St Helena - an annotated checklist. British Ornithologists Union, Tring

R Development Core Team (2014) R: a language and environment for statistical computing. R Foundation for Statistical Computing, Vienna, Austria, http://www.R-project.org/

Shaffer TL (2004) A unified approach to analyzing nest success. Auk 121:526-540

Sommerfeld J, Hennicke JC (2010) Comparison of trip duration, activity pattern and diving behaviour by Red-tailed Tropicbirds (Phaethon rubricauda) during incubation and chick-rearing. Emu 110:78-86

Sommerfeld J, Kato A, Ropert-Coudert Y, Garthe S, Hindell MA (2013a) Foraging parameters influencing the detection and interpretation of area-restricted search behaviour in marine predators: a case study with the Masked Booby. PLoS ONE 8:e63742

Sommerfeld J, Kato A, Ropert-Coudert Y, Garthe S, Hindell MA (2013b) The individual counts: within sex differences in foraging strategies are as important as sex-specific differences in masked boobies Sula dactylatra. J Avian Biol 44:531-540

Sommerfeld J, Kato A, Ropert-Coudert Y, Garthe S, Wilcox C, Hindell MA (2015) Flexible foraging behaviour in a marine predator, the Masked booby (Sula dactylatra), according to foraging locations and environmental conditions. J Exp Mar Biol Ecol 463:79-86

Stonehouse B (1962) Ascension Island and the British Ornithologists' Union Centenary Expedition 1957-59. Ibis 103b:107-123

Stonehouse B (1963a) The laying dates of some St Helenan sea-birds, 1958-59. Ibis 103b:480-482

Stonehouse S (1963b) The Frigate Bird Fregata aquila of Ascension Island. Ibis 103b:409-422

Szostek KL, Becker PH, Meyer BC, Sudmann SR, Zintl H (2013) Colony size and not nest density drives reproductive output in the Common Tern Sterna hirundo. Ibis 156:48-59

Thaxter C, Lascelles B, Sugar K, Cook AS, Roos S, Bolton M, Langston R, Burton NH (2012) Seabird foraging ranges as a preliminary tool for identifying candidate Marine Protected Areas. Biol Conserv 156: 53-61

Tuck GN, Phillips RA, Small C, Thomson RB, Klaer NL, Taylor F, Wanless RM, Arrizabalaga H (2011) An assessment of seabirdfishery interactions in the Atlantic Ocean. ICES J Mar Sci 68: $1628-1637$

Votier SC, Bearhop S, Witt MJ, Inger R, Thompson D, Newton J (2010) Individual responses of seabirds to commercial fisheries revealed using GPS tracking, stable isotopes and vessel monitoring systems. J Appl Ecol 47:487-497

Wakefield ED, Bodey TW, Bearhop S et al (2013) Space partitioning without territoriality in gannets. Science 341:68-70

Weimerskirch $\mathrm{H}$ (2007) Are seabirds foraging for unpredictable resources? Deep-Sea Res Pt II 54:211-223 
Weimerskirch H, Salamolard M, Sarrazin F, Jouventin P (1993) Foraging strategy of wandering albatrosses through the breeding season: a study using satellite telemetry. Auk 110:325-342

Weimerskirch H, le Corre M, Jaquemet S, Marsac F (2005) Foraging strategy of a tropical seabird, the red-footed booby, in a dynamic marine environment. Mar Ecol Prog Ser 288:251-261

Weimerskirch H, le Corre M, Bost CA (2008) Foraging strategy of masked boobies from the largest colony in the world: relationship to environmental conditions and fisheries. Mar Ecol Prog Ser 362: 291-302

Weimerskirch H, le Corre M, Gadenne H, Pinaud D, Kato A, RopertCoudert Y, Bost C-A (2009) Relationship between reversed sexual dimorphism, breeding investment and foraging ecology in a pelagic seabird, the masked booby. Oecologia 161:637-649
Wittenberger JF, Hunt GL (1985) The adaptive significance of coloniality in birds. In: Farner DS, King JR (eds) Avian Biology. Academic Press, San Diego, pp 1-78

Woo KJ, Elliott KH, Davidson M, Gaston AJ, Davoren GK (2008) Individual specialization in diet by a generalist marine predator reflects specialization in foraging behaviour. J Anim Ecol 77:10821091

Yeh YM, Huang HW, Dietrich KS, Melvin E (2013) Estimates of seabird incidental catch by pelagic longline fisheries in the South Atlantic Ocean. Anim Conserv 16:141-152

Young HS, Shaffer SA, McCauley DJ, Foley DG, Dirzo R, Block BA (2010) Resource partitioning by species but not sex in sympatric boobies in the central Pacific Ocean. Mar Ecol Prog Ser 403:291301 